\title{
Implementasi Logika Fuzzy Dalam Optimasi Jumlah Produksi Barang Menggunakan Metode Tsukamoto (Studi Kasus : Toko XYZ Putih Situbondo)
}

Implementation of Fuzzy Logic in Optimizing Total Goods Production

Using the Tsukamoto Method (Case Study: Situbondo White XYZ Store)

\section{Sri Mulyati}

Jurusan Teknik Informatika Universitas Muhammadiyah Tangerang Jalan Perintis Kemerdekaan I Babakan No.33, RT.007/RW.003, Cikokol, Tangerang

lilysrimulyati@umt.ac.id

\begin{abstract}
Optimization of the amount of goods produced is carried out using three variables, namely demand, supply and production. The sales variable consists of two fuzzy sets, namely: down and up, the inventory variable consists of two fuzzy sets, namely: a little and a lot, while the procurement variable consists of two fuzzy sets, namely decreasing and increasing. By combining all these fuzzy sets, four fuzzy rules are obtained, which are then used in each inference. In the inference stage, the antecedent membership value $(\alpha)$ and the procurement estimate optimization value $(z)$ are sought for each rule. Optimization of procurement of goods $(z)$ is sought using the centralized average defuzzification method. The analysis using the Tsukamoto method resulted in the production amount that must be produced, which is around 2370 with a demand condition of 2500 and inventory in the warehouse of 100 bottles. The analysis using the Tsukamoto method shows the real conditions that must be carried out by the seller of the goods at the Situbondo White Sand Shell Shop in the process of producing goods to make them more targeted.
\end{abstract}

Keywords: Production, Goods, Fuzzy Method, Tsukamoto Method

\begin{abstract}
Abstrak
Optimasi jumlah produksi barang dilakukan dengan menggunakan tiga variabel, yaitu permintaan, persediaan dan produksi. Variabel penjualan terdiri dari dua himpunan fuzzy, yaitu : turun dan naik, variabel persediaan terdiri dari dua himpunan fuzzy, yaitu : sedikit dan banyak, sedangkan variabel pengadaan terdiri dari dua himpunan fuzzy, yaitu berkurang dan bertambah. Dengan mengkombinasikan semua himpunan fuzzy tersebut, diperoleh empat aturan fuzzy, yang selanjutnya digunakan dalam setiap inferensi. Pada tahap inferensi, dicari nilai keanggotaan anteseden $(\alpha)$ dan nilai optimasi perkiraan pengadaan $(z)$ dari setiap aturan. Optimasi pengadaan barang $(z)$ dicari dengan metode defuzzifikasi rata-rata terpusat. Analisa dengan menggunakan metode Tsukamoto menghasilkan jumlah produksi yang harus di produksi yaitu sekitar $\mathbf{2 3 7 0}$ dengan kondisi permintaan sebanyak 2500 dan persediaan di Gudang sebesar 100 botol. Analisa dengan menggunakan metode Tsukamoto ini memperlihatkan kondisi rill yang harus dijalankan pihak penjual barang di Toko Kerang Pasir Putih Situbondo dalam melakukan proses produksi barang supaya lebih tepat sasaran.
\end{abstract}

Kata Kunci : Produksi, Barang, Metode Fuzzy, Metode Tsukamoto 


\section{PENDAHULUAN}

(Ula, 2014)Sistem pengambilan keputusan merupakan bagian yang tak terpisahkan dari totalitas sistem organisasi keseluruhan. Bahwa sistem organisasi paling tidak mencakup sistem fisik (sistem operasional), sistem manajemen (sistem keputusan), dan sistem informasi. Sistem informasi dibuat agar mempermudah dalam pengelolaan data maupun informasi serta memudahkan dalam mencari data maupun informasi tersebut. Perubahan struktur pasar, kebutuhan dan yang lainnya terus terjadi sehingga berpengaruh pada kebijaksanaan manajemen yang dijalankan, salah satu kiat untuk mensiasati problematika tersebut adalah dengan mengembangkan serta meningkat potensi sumberdaya yang tersedia. (Nasibu, 2009)Demi efisiensi dan efektifitas kerja maka pengambilan keputusan yang tepat sangat diperlukan.

Toko Kerang Pasir Putih Situbondo merupakan toko yang menjual tempat tisu dari bahan dasar kerang. Dalam aktivitas bisnisnya Toko Kerang Pasir Putih Situbondo masih belum ada analis untuk membuat optimasi dari produksi barang sehingga barang tersebut mempunyai sisa yang banyak dan sisa tersebut di tempatkan di Gudang , sering Gudang tersebut penuh karena kelebihan produksi yang dihasilkan. Maka dari itu Toko Kerang Pasir Putih Situbondo membutuhkan suatu sistem analisa yang dapat memperkirakan jumlah produksi yang di hasilkan dari data permintaan dan data persediaan yang ada di Gudang agar tidak terjadinya produksi berlebih. Oleh karena itu analisa ini dibuat untuk mencegah terjadinya produksi yang berlebihan. Hal tersebut akan menjadi efisien dan dapat mengurangi biaya produksi dari toko tersebut.

\section{Metode Pengumpulan Data}

\section{METODE PENELITIAN}

Metodelogi penelitian dapat digunakan sebagai tahapan untuk memberi arahan terhadap langkah yang digunakan dalam permasalahan yang diambil dalam penelitian. Langkah-langkah yang dilakukan dimulai dengan mengidentifikasi dan analisa kebutuhan data, mendeskripsikan sistem yang akan dikembangkan, mengolah data, serta melakukan uji coba berhubungan sistem yang dibangun.

\section{Alat dan Bahan}

Untuk membangun sistem diperlukan perangkat keras dan perangkat lunak komputer menggambarkan alat dan bahan yang digunakan untuk kelancaran program. Kebutuhan dan alat yang dibutuhkan ada beberapa yaitu :

a. Kebutuhan Perangkat Keras

1) Prosesor intel Core i5 $3.4 \mathrm{Ghz}$

2) Hardisk $500 \mathrm{~GB}$

3) Memory DDR4 8 GB

4) LCD Screen 14"

5) Keyboard, Mouse

b. Kebutuhan Perangkat Lunak

1) Sistem Operasi Windows 10

2) Microsoft Word 2013

3) LabView 2014 


\section{Flowchart Sistem Fuzzy}

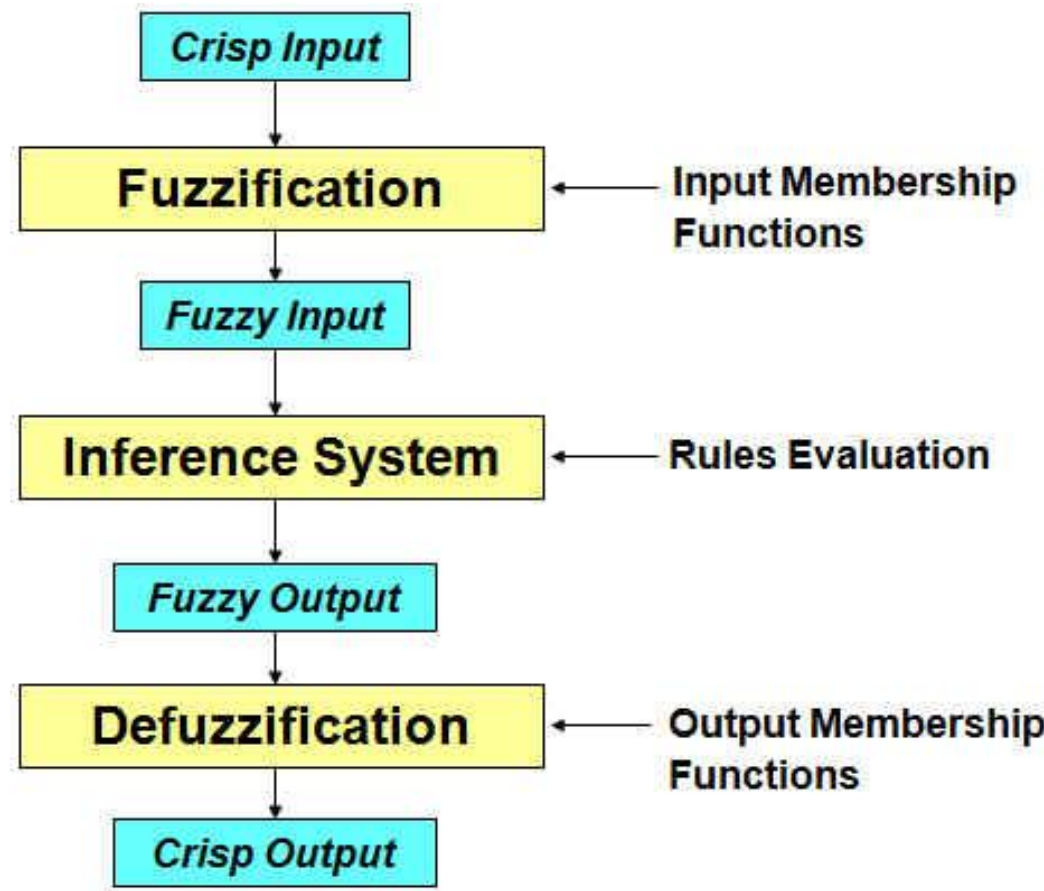

Gambar 1 Flowchart perhitungan dengan Fuzzy

HASIL DAN PEMBAHASAN

1. Analisa Sistem

Produksi barang di Toko Kerang Pasir Putih Situbondo saat ini berlangsung pada umumnya, setiap barang yang di minta oleh konsumen cukup untuk memenuhi permintaan. Tetapi terkadang karna toko tersebut masih menggunakan sistem manual jadi hanya mengandalkan dari permintaan yang ada mereka membuat produksi barang terlalu banyak sehingga barang yang tidak terjual tersimpan di Gudang cukup banyak dan hal tersebut bisa merugikan toko tersebut karena pemborosan dana yang cukup banyak. Dengan adanya analisa ini, maka diharapkan dalam proses pelaksanaan penjualan produk menjadi lebih optimal dan meningkat. Dengan kata lain untuk melakukan fungsi pengolahan data, menerima masukan (input) dan menghasilkan keluaran (output) berupa informasi sebagai dasar bagi pengambilan keputusan guna mencapai suatu tujuan. Untuk masalah ini toko saat ini sedang mendapatkan permintaan sebesar 2500 buah dan persediaan digudang hanya 100 botol. Data ini akan menjadi dasar untuk analisa fuzzy menggunakan metode tsukamoto.

2. Perhitungan Fuzzy Metode Tsukamoto

Penyelesaian masalah untuk kasus pengadaan barang menggunakan Logika Fuzzy metode Tsukamoto adalah sebagai berikut :

a. Menentukan Variabel yang terkait dalam proses yang akan ditentukan dan fungsi fuzzyfikasi yang sesuai. Pada kasus ini, ada 3 variabel yang akan dimodelkan, yaitu: 
1) Variabel permintaan $[\mathrm{x}]$, terbagi menjadi 2 himpunan fuzzy, yaitu naik dan turun. Berdasarkan dari data permintaan terbesar $=4000$ buah dan terkecil $=500$ buah , maka fungsi keanggotaan dirumuskan sebagai berikut :

$$
\begin{aligned}
& \mu \text { PermintaanTURUN }[2500]=\frac{(4000-2500)}{400 n-50 n}=\frac{1500}{3.50 n}=0.43 \\
& \mu \text { PermintaanNAIK }[2500]=\frac{(2500-500)}{40 n n-50 n}=\frac{2000}{350 n}=0.57
\end{aligned}
$$

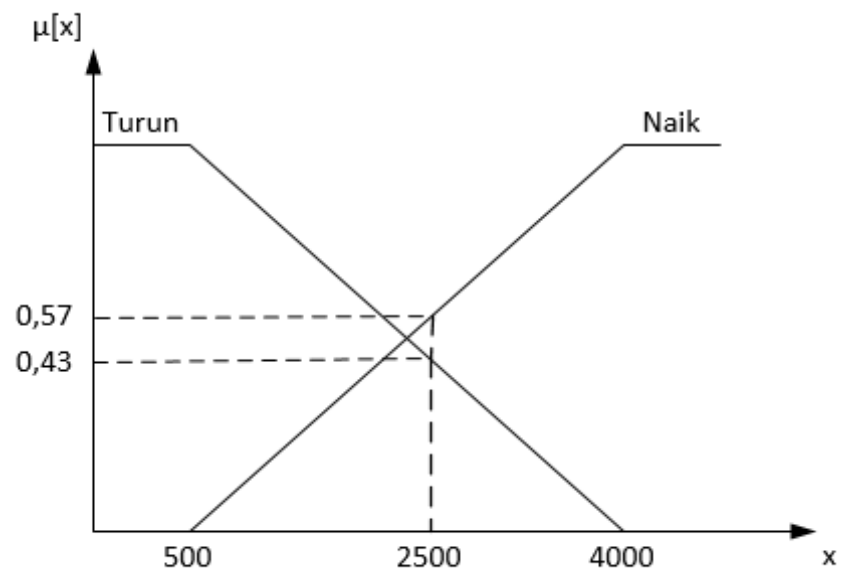

Gambar 3 Kurva Variabel Permintaan

2) Variabel persediaan [x], terbagi menjadi 2 himpunan fuzzy, yaitu Banyak dan Sedikit. Berdasarkan dari data persediaan terbesar $=300$ buah dan terkecil $=75$ buah , maka fungsi keanggotaan dirumuskan sebagai berikut :

$$
\begin{aligned}
& \mu \text { PersediaanSEDIKIT }[100]=\frac{(300-100)}{30 n-75}=\frac{200}{225}=0.89 \\
& \mu \text { PersediaanBANYAK }[100]=\frac{(100-75)}{30 n-75}=\frac{25}{225}=0.11
\end{aligned}
$$

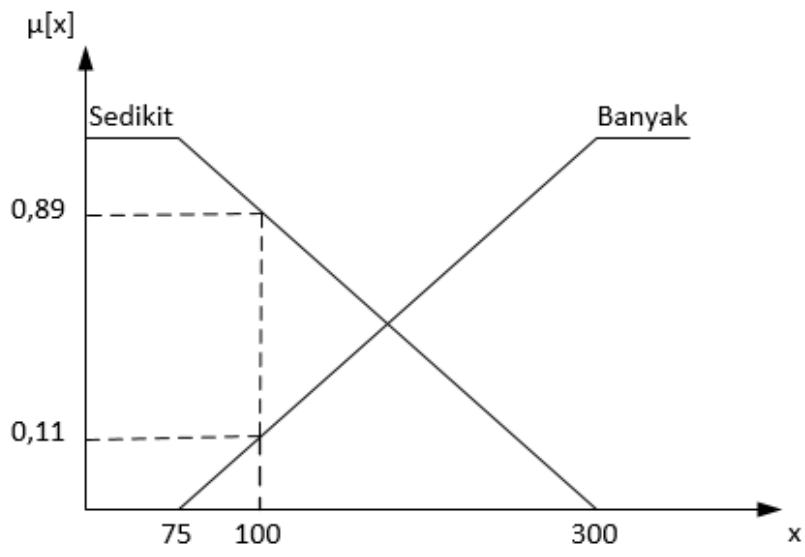

Gambar 4 Kurva Variabel Persediaan 
3) Variabel produksi $[\mathrm{x}]$, terbagi menjadi 2 himpunan fuzzy, yaitu Bertambah dan Berkurang. Berdasarkan dari data produksi terbesar $=4500$ buah dan terkecil $=1000$ buah, maka fungsi keanggotaan dirumuskan sebagai berikut :

$$
\begin{aligned}
& \mu \text { ProduksiBERKURANG }[z]=\frac{(4500-z)}{450 n-1000}=\frac{(4500-z)}{350 n} \\
& \mu \text { ProduksiBERTAMBAH }[z]=\frac{(z-1000)}{450 n-10 n n}=\frac{(z-1000)}{35 n n}
\end{aligned}
$$

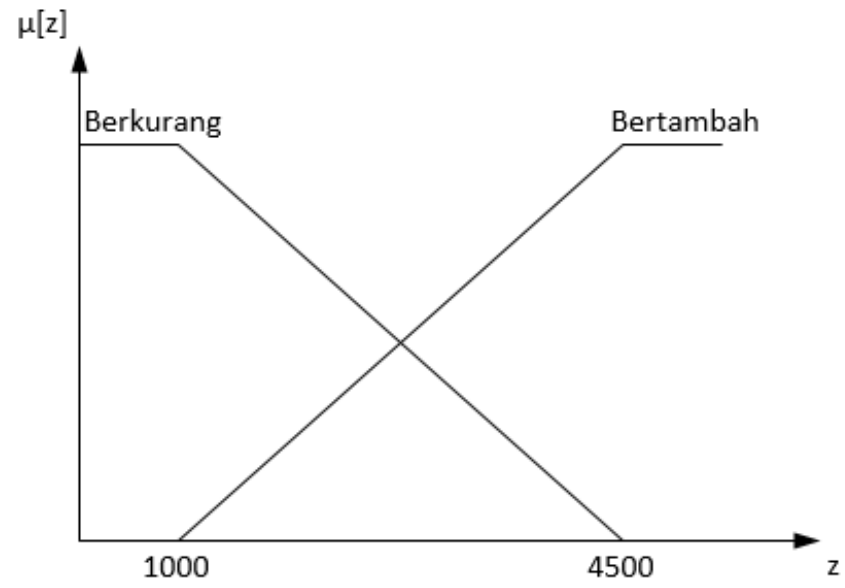

Gambar 5 Kurva Variabel Produksi

4) Substitusi Rules/Aturan kepada rumus z

a) Rules 1 : Jika Permintaan TURUN dan Persediaan BANYAK, maka Produksi Barang BERKURANG

$$
\alpha-\text { Predikat }_{1}=\mu \text { PermintaanTURUN } \cap \mu \text { PersediaanBANYAK }
$$

$=\operatorname{MIN}(\mu$ PermintaanTURUN $[2500], \mu$ PersediaanBANYAK $[100])$

$$
\begin{aligned}
& =\operatorname{MIN}(0.43 ; 0.11) \\
& =0.11
\end{aligned}
$$

Subtitusi ke rumus Himpunan Produksi Berkurang

$$
\mu \text { ProduksiBERKURANG }[z]=\frac{(4500-z)}{3500}
$$




$$
0.11=\frac{(4500-z)}{3500}
$$$$
z_{1}=4115
$$

b) Rules 2 :Jika Permintaan TURUN dan Persediaan SEDIKIT, maka Produksi Barang BERKURANG

$$
\alpha-\text { Predikat }_{2}=\mu \text { PermintaanTURUN } \cap \mu \text { PersediaanSEDIKIT }
$$

$=\operatorname{MIN}(\mu$ PermintaanTURUN $[2500], \mu$ PersediaanSEDIKIT $[100])$

$$
\begin{aligned}
& =\operatorname{MIN}(0.43 ; 0.89) \\
& =0.43
\end{aligned}
$$

Subtitusi ke rumus Himpunan Produksi Berkurang

$$
\begin{gathered}
\mu \text { ProduksiBERKURANG }[z]=\frac{(4500-z)}{3500} \\
0.43=\frac{(4500-z)}{3500} \\
z_{2}=2995
\end{gathered}
$$

c) Rules 3 :Jika Permintaan NAIK dan Persediaan BANYAK, maka Produksi Barang BERTAMBAH

$$
\begin{gathered}
\alpha-\text { Predikat }_{3}=\mu \text { PermintaanNAIK } \cap \mu \text { PersediaanBANYAK } \\
\begin{array}{r}
\text { MIN }(\mu \text { PermintaanNAIK }[2500], \mu \text { PersediaanBANYAK }[100]) \\
=\operatorname{MIN}(0.57 ; 0.11) \\
=0.11
\end{array}
\end{gathered}
$$

Subtitusi ke rumus Himpunan Produksi Bertambah

$$
\begin{gathered}
\mu \text { ProduksiBERTAMBAH }[z]=\frac{(z-1000)}{3500} \\
0.11=\frac{(z-1000)}{3500} \\
z_{3}=1385
\end{gathered}
$$


JTS : Jurnal Teknik

P-ISSN: 2302-8734

E-ISSN: 2581-0006
Vol. 9 No. 2 Th. 2020

Halaman : 66 - 77

November 2020

d) Rules 4 :Jika Permintaan NAIK dan Persediaan SEDIKIT, maka Produksi Barang BERTAMBAH

$$
\begin{aligned}
& \alpha-\text { Predikat }_{4}=\mu \text { PermintaanNAIK } \cap \mu \text { PersediaanSEDIKIT } \\
& \begin{aligned}
=\operatorname{MIN}\left(\mu \text { PermintaanNAIK }^{2}\right. & 2500], \mu \text { PersediaanSEDIKIT }[100]) \\
& =\operatorname{MIN}(0.57 ; 0.89) \\
& =0.57
\end{aligned}
\end{aligned}
$$

Subtitusi ke rumus Himpunan Produksi Bertambah

$$
\begin{aligned}
\mu \text { ProduksiBERKURANG }[z] & =\frac{(z-1000)}{3500} \\
0.57 & =\frac{(z-1000)}{3500} \\
z_{4} & =2995
\end{aligned}
$$

5) Mencari Nilai z

$$
\begin{aligned}
& z=\frac{\alpha \text { Pred }_{1} \cdot Z_{1}+\alpha \text { Pred }_{2} . Z_{2}+\alpha \text { Pred }_{3} . Z_{3}+\alpha \text { Pred }_{4} . Z_{4}}{\alpha \text { Pred }_{1}+\alpha \text { Pred }_{2}+\alpha \text { Pred }_{3}+\alpha \text { Pred }_{4}} \\
& z=\frac{0,11 \cdot 4115+0,43 \cdot 2995+0,11 \cdot 1385+0,57 \cdot 2995}{0,11+0,43+0,11+0,57} \\
& z=\frac{180000}{61} \\
& z=2954
\end{aligned}
$$




\section{ImpelentasI}

a. Variables

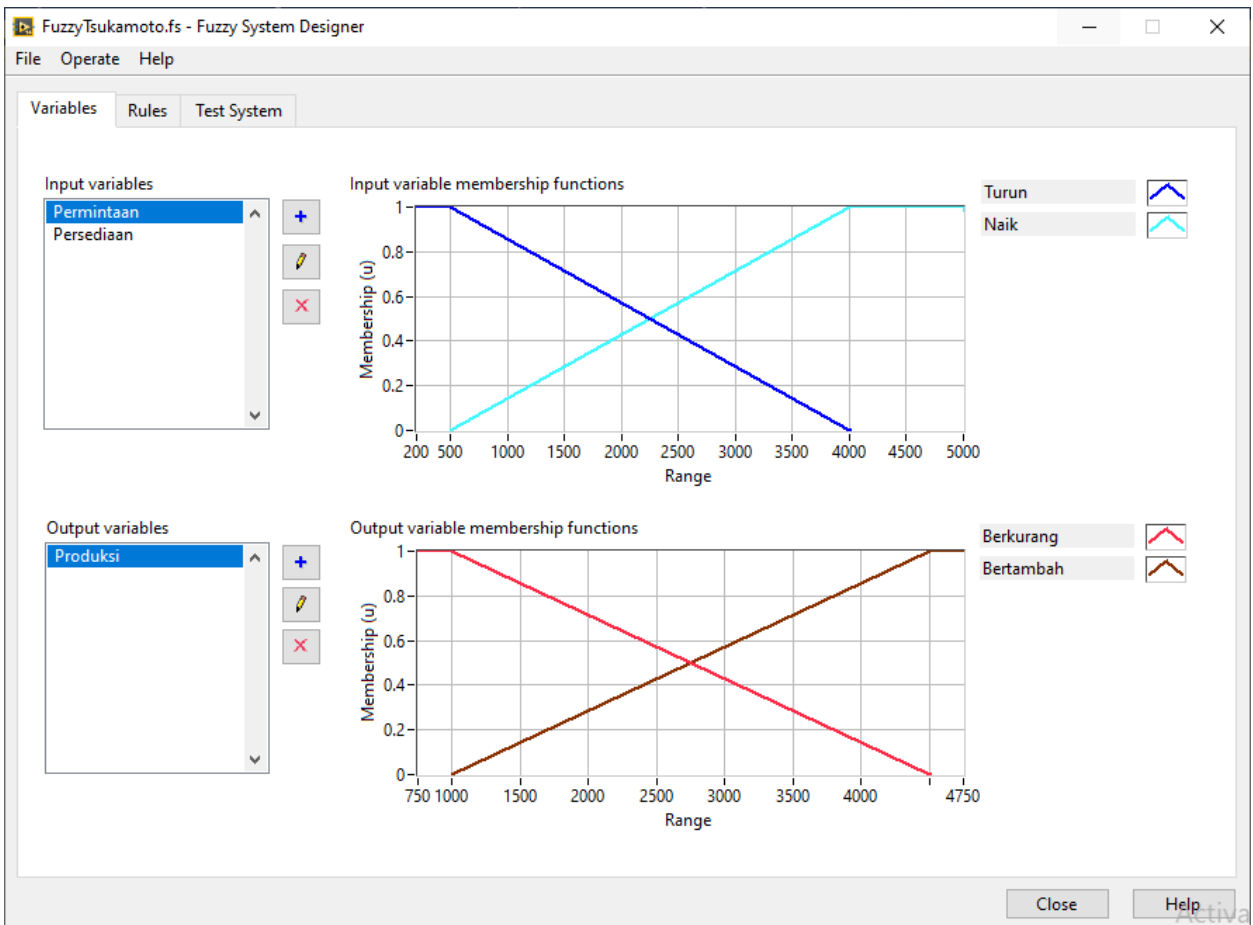

Gambar 6 Halaman Variables

Pada halaman variable ini digunakan untuk memasukan data variable dan juga memberikan nama pada variable tersebut, pada kasus ini digunakan 2 variabel input yaitu variable permintaan dan juga variable persediaan. Untuk keluaran digunakan 1 variable yang diberi nama produksi.

b. Rules

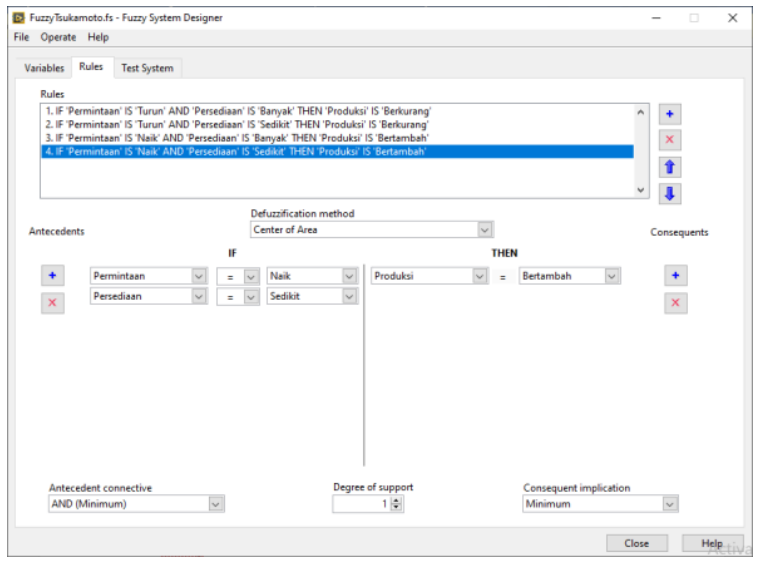

http://jurnal.umt.ac.id/index.php/it/index 


\section{Gambar 7 Halaman Rules}

Pada halaman rules ini digunakan untuk membuat suatu aturan yang berlaku pada logika fuzzy. Pada kasus ini digunakan hanya 4 rules. Yang digunakan hanya 4 rules karena input yang dipakai hanya 2 dan output yang di pakai juga hanya 1 jadi untuk membuat sebuah rules hanya bisa digunakan 4 rules

\section{c. Test Sistem}

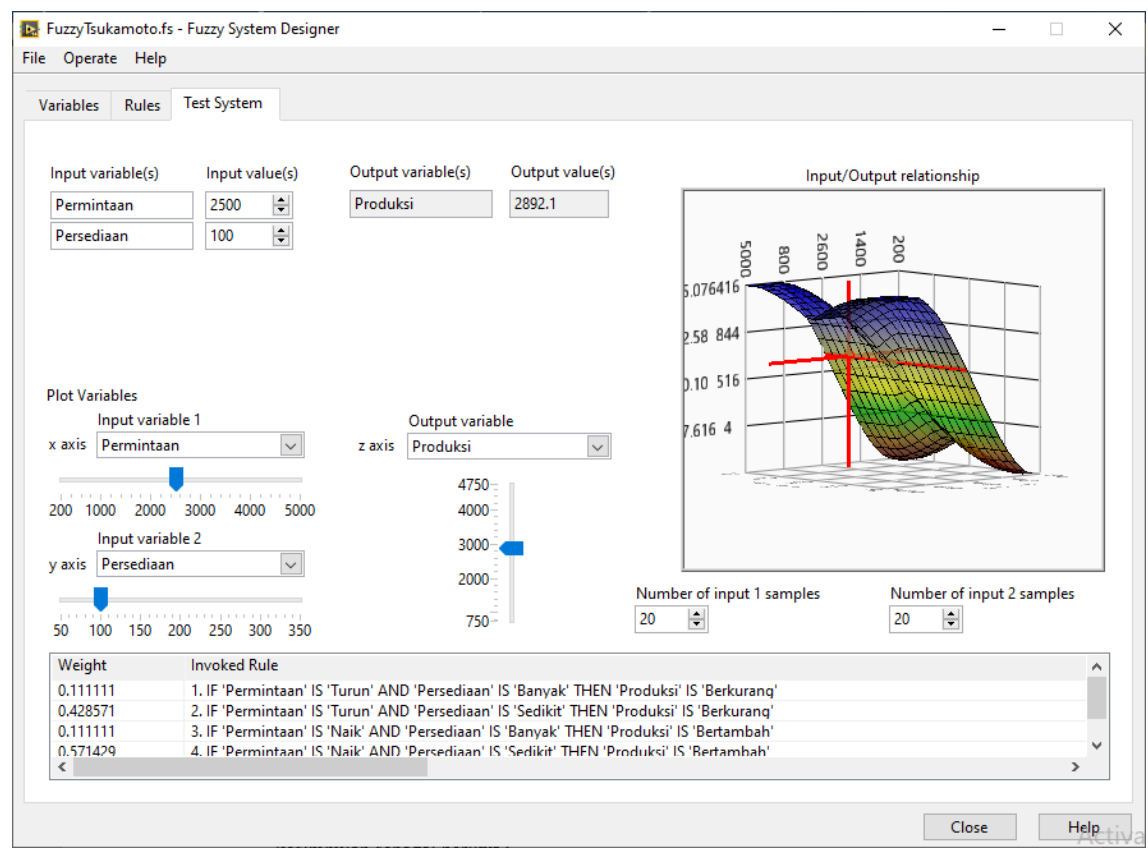

Gambar 8 Halaman Test System

Pada halaman ini yaitu halaman test system yang berguna untuk melakukan simulasi dari beberapa variable dan juga rules yang sudah kita masukan. Untuk cara mensimulasikannya dengan memasukan nilai variable permintaan dan nilai variable persediaan. Pada system test juga terdapat surface yaitu grafik yang menunjukan hasil dari logika fuzzy tersebut 
JTS : Jurnal Teknik

P-ISSN: 2302-8734

E-ISSN: 2581-0006
Vol. 9 No. 2 Th. 2020

Halaman : 66 - 77

November 2020

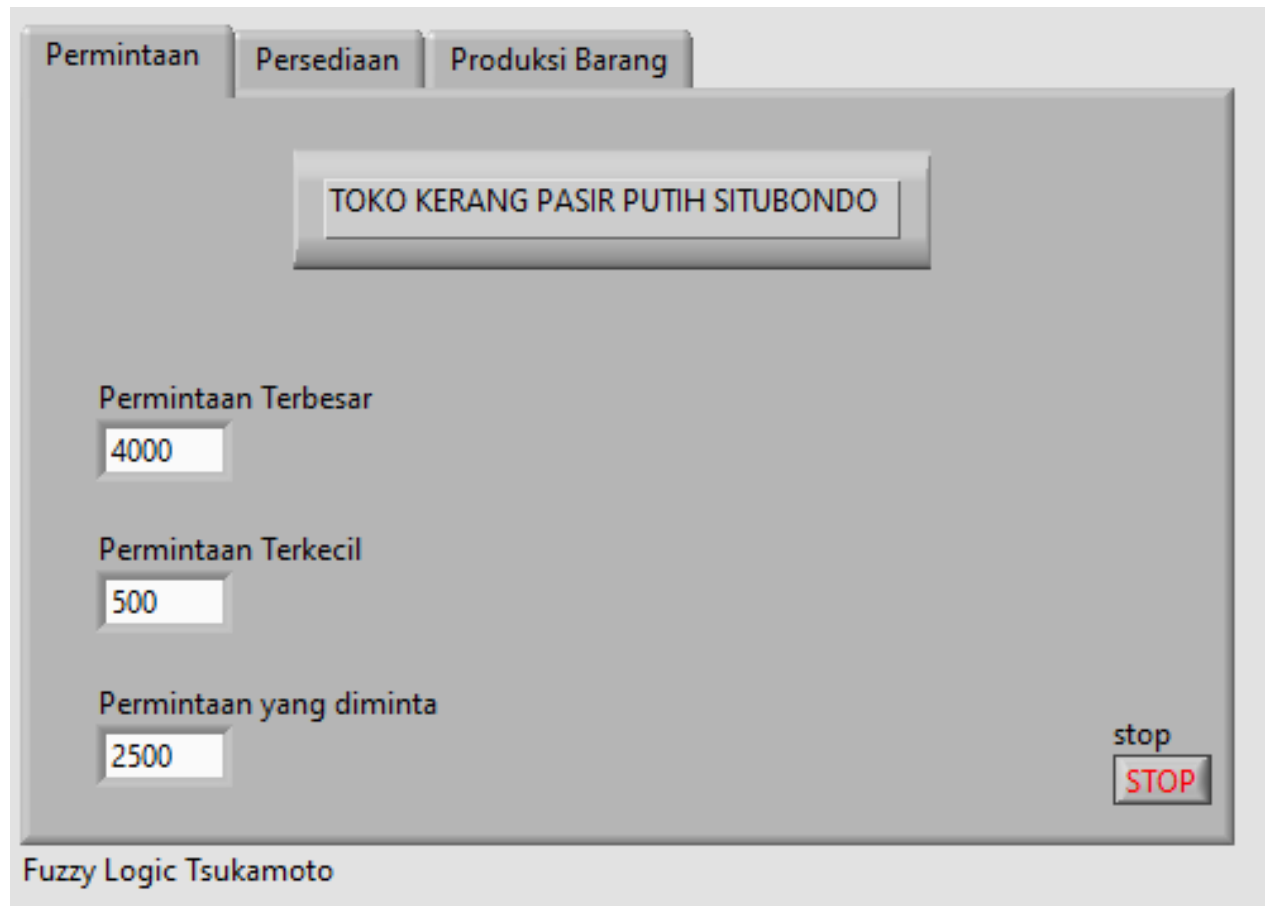

Gambar 9 Nilai Input Permintaan

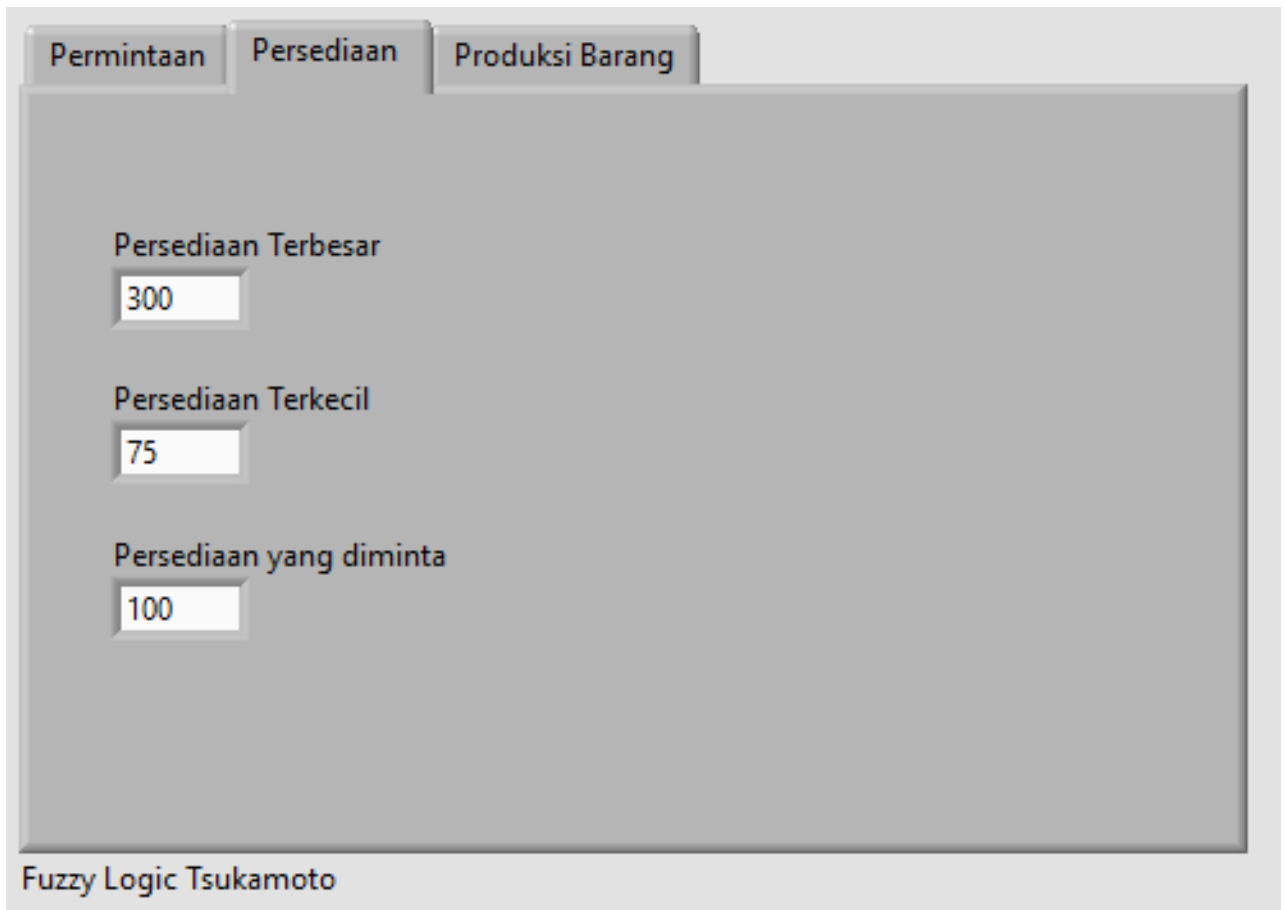

Gambar 10 Nilai Input Persediaan 


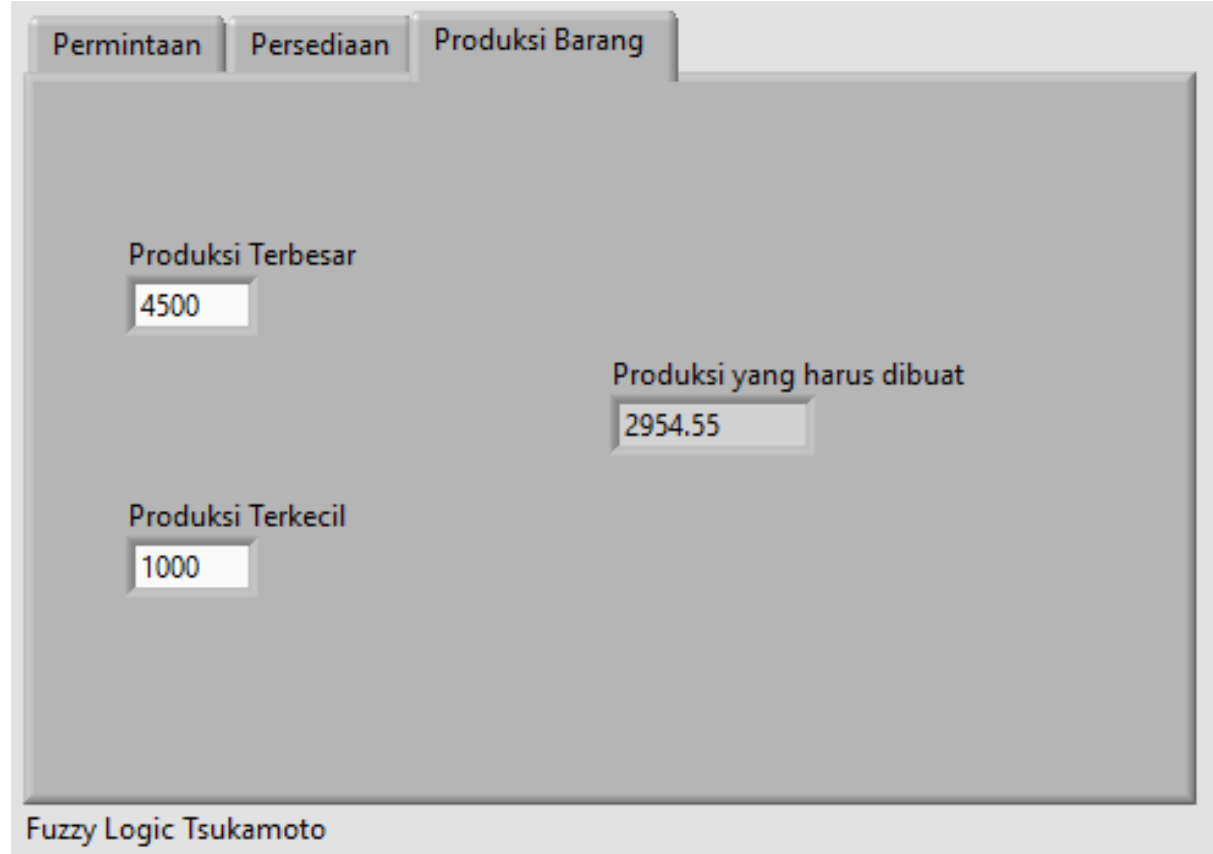

Gambar 11 Hasil Produksi yang dibuat

\section{Kesimpulan}

\section{KESIMPULAN DAN SARAN}

Berdasarkan hasil analisis dan perancangan sistem optimasi jumlah pengadaan barang menggunakan algoritma Fuzzy metode Tsukamoto, maka dapat diambil kesimpulan sebagai berikut :

a. Sistem optimasi jumlah pengadaan barang menggunakan algoritma fuzzy metode Tsukamoto ini tepat digunakan oleh pihak penjual barang di Toko Kerang Pasir Putih Situbondo dapat dilihat data permintaan dan persediaan untuk mengetahui data produksi optimum yang harus di hasilkan.

b. Kondisi optimum diperoleh untuk produksi barang menggunakan metode Tsukamoto mencapai 2981 buah/hari.

\section{Saran}

Berikut ini adalah saran yang mungkin dapat digunakan untuk pengembangan sistem lebih lanjut :

a. Dapat dikembangkan dengan cara menggunakan aplikasi MatLab agar mempermudah dalam proses analisa dan pengolahan data.

b. Untuk mendapatkan perbandingan di dalam pencarian dengan menggunakan logika fuzzy, perlu dilanjutkan dengan menggunakan metode yang lain seperti metode Sugeno dan metode Mamdani

\section{DAFTAR PUSTAKA}

Akhir Maulana, Y., \& Nurhadiyono, B. (2017). Implementasi Fuzzy Tsukamoto Dalam Mendiagnosa. Ilmu Komputer(KLIK), 04(02), 233-246. Retrieved from maulanayanmas@gmail.com 
Kanani, N., \& Thakker, M. (n.d.). Low Cost Data Acquisition System Using LABVIEW, $I I I(\mathrm{I})$.

Kaswidjanti, W. (2014). Implementasi Fuzzy Inference System Metode Tsukamoto Pada Pengambilan Keputusan Pemberian Kredit Pemilikan Rumah. Telematika, 10(2). https://doi.org/10.31315/telematika.v10i2.281

Nasibu, I. Z. (2009). Penerapan Metode AHP Dalam Sistem Pendukung Keputusan Penempatan Karyawan Menggunakan Aplikasi Expert Choice.

Riyadi Yudha Wiguna, Hanny Haryanto, S.Kom, M. . (2015). Sistem berbasis aturan menggunakan logika fuzzy tsukamoto untuk prediksi jumlah produksi roti pada cv. gendis bakery. Program Studi Teknik Informatika, Fakultas Ilmu Komputer, Universitas Dian Nuswantoro.

Sari, N. R., \& Mahmudy, W. F. (2015). Fuzzy Inference System Tsukamoto Untuk Menentukan Kelayakan Calon Pegawai. Seminar Nasional Sistem Informasi Indonesia, (November), 2-3.

Sejati W.P., Y., Kristanto, H., \& Karel T, J. (n.d.). Implementasi Fuzzy Set Dan Fuzzy Infekence System, (1).

Ula, M. (2014). Implementasi Logika Fuzzy Dalam Optimasi Jumlah Pengadaan Barang Menggunakan Metode Tsukamoto (Studi Kasus: Toko Kain My Text). Jurnal ECOTIPE, 1(2), 36-46.

W, D. A., Mt, I. P., Bambang, I., Mt, S., \& Haryono, J. M. T. (2013). APLIKASI PENGENDALI SUHU RUANGAN DENGAN KONTROLER LOGIKA FUZZY BERBASIS MIKROKONTROLER AVR-ATMEGA 328. Universitas Brawijaya, 1(3), 1-5.

Wijaya, Y. P. (2016). Simulasi Pengendalian Volume Tangki menggunakan LabVIEW dan Arduino UNO. Jurnal Sains Dan Teknologi Industri, 13(1), 79-82. Retrieved from http://ejournal.uin-suska.ac.id/index.php/sitekin/article/view/1293

Scribd (2015, 14 Januari). Contoh Soal Fuzzy Metode Tsukamoto.Dikutip 16 Desember 2019 : https://www.scribd.com/doc/252591115/Contoh-Soal-Fuzzy-Metode-Tsukamoto 